\title{
Adherence to Non-Selective Beta Blockers for Prevention of Variceal Bleeding in Cirrhotic Patients
}

\author{
Yang $A n^{1-3, *}$ \\ Xiangbo $X u^{1-3, *}$ \\ Tianshu Ren ${ }^{1-3, *}$ \\ Zhenhua Tong ${ }^{1,4, *}$ \\ Fernando Gomes Romeiro ${ }^{5}$ \\ Andrea Mancuso ${ }^{6}$ \\ Xiaozhong Guo' \\ Xingshun Qi (iD) \\ 'Liver Cirrhosis Study Group, \\ Department of Gastroenterology, \\ General Hospital of Northern Theater \\ Command, Shenyang, I I0840, People's \\ Republic of China; ${ }^{2}$ Postgraduate College, \\ Shenyang Pharmaceutical University, \\ Shenyang, I10016, People's Republic of \\ China; ${ }^{3}$ Department of Pharmacy, \\ General Hospital of Northern Theater \\ Command, Shenyang, I 10840, People's \\ Republic of China; ${ }^{4}$ Section of Medical \\ Service, General Hospital of Northern \\ Theater Command, Shenyang, I I0840, \\ People's Republic of China; ${ }^{5}$ Department \\ of Internal Medicine, Botucatu Medical \\ School, UNESP - Univ Estadual Paulista. \\ Av. Prof. Mário Rubens Guimarães \\ Montenegro, s/n Distrito de Rubião Jr, \\ Botucatu, Brazil; ${ }^{6}$ Medicina Interna I, \\ ARNAS-Civico, Di Cristina-Benfratelli, \\ Palermo, Italy
}

*These authors contributed equally to this work
Background and Aim: Long-term use of non-selective beta blockers (NSBBs) is essential for the prevention of esophageal variceal bleeding in liver cirrhosis but may impair the patient's adherence. The present study aimed to investigate the adherence to NSBBs to prevent variceal bleeding in cirrhotic patients.

Methods: All patients who had an indication of NSBBs for the prophylaxis of variceal bleeding between February 2018 and June 2019 were screened. Clinical pharmacists gave pre-medication education and recorded the adherence to NSBBs during the patients' hospitalizations. Factors associated with poor adherence were evaluated by univariate logistic regression analysis. Odds ratios (OR) with 95\% confidence intervals (CI) were calculated. The relationship between poor adherence during follow-up and variceal bleeding after discharge was also evaluated.

Results: Overall, 108 patients were screened, of whom 12 were intolerant to NSBBs. Among the 96 remaining patients who could take NSBBs, the average change of heart rate after NSBBs was -10.49 b.p.m. Twenty-two (22.9\%) patients had poor adherence to NSBBs due to their refusal to take NSBBs $(n=2)$, complete forgetfulness to take NSBBs $(n=10)$, and refusal or forgetfulness to monitor heart rate $(n=10)$. Univariate logistic regression analysis demonstrated that only older age was significantly associated with poor adherence (OR: 1.065, 95\% CI: 1.019-1.114, P = 0.005). Patients with poor adherence during follow-up were more likely to develop variceal bleeding after discharge.

Conclusion: A significant proportion of cirrhotic patients had poor adherence to NSBBs during their hospitalizations. Further studies should explore how to improve the patient's adherence to NSBBs.

Keywords: liver cirrhosis, esophageal varices, non-selective beta blockers, adherence, risk factors

\section{Introduction}

Esophageal varices, one of common complications of liver cirrhosis, are found in about half of cirrhotic patients at the time of initial diagnosis. ${ }^{1}$ Esophageal variceal bleeding is usually life-threatening with a mortality of $5-20 \%{ }^{2,3}$ Patients who have survived from acute esophageal variceal bleeding are at a high risk of rebleeding without secondary prophylaxis and the incidence of rebleeding can be up to $70 \%{ }^{3,4}$ According to the current practice guidelines and consensus, non-selective beta blockers (NSBBs), which are cheap with few contraindications and relatively low intolerance, are the main treatment strategy for preventing from esophageal variceal bleeding and rebleeding, ${ }^{5-8}$ and should be titrated to the maximum tolerated dosage to reach the therapeutic goal. ${ }^{9}$ NSBBs can reduce the portal pressure, thereby
Correspondence: Xingshun Qi;

Xiaozhong Guo

Email xingshunqi@I26.com;

guo_xiao_zhong@I26.com 
decreasing the incidence of first variceal bleeding by about $43 \%^{10,11}$ and increasing the incidence of free of variceal rebleeding by about $21 \%{ }^{12}$ Notably, NSBBs can achieve hemodynamic response in only one-third to half of cirrhotic patients. ${ }^{13,14}$ Even if NSBBs do not meet the ideal goal of reducing the portal pressure in some patients, it still has some other benefits on decreasing the occurrence of complications, such as ascites and spontaneous bacterial peritonitis. $^{15-17}$

Good adherence to any medication is crucial for the patient care and indispensable for reaching the clinical goals, and has a significant impact on the effectiveness of clinical treatment and health recovery. ${ }^{18,19}$ Generally, an adherence rate of over $80 \%$ will improve clinical outcomes. $^{20}$ By contrast, poor adherence may lead to increased medical costs, decreased efficacy, ${ }^{21}$ and early disease recurrence. ${ }^{22}$ In cirrhotic patients who need to take NSBBs chronically, clinical success and prognosis are also dependent upon the adherence to NSBBs. ${ }^{15,23}$ However, heart rates and blood pressures should be closely monitored during the use of NSBBs, and some adverse reactions of NSBBs are common, including fatigue, shortness of breath, symptomatic hypotension, bradycardia and conduction defects, and sleep disturbance, ${ }^{13}$ which may greatly affect the patient's adherence.

Herein, the present study primarily aimed to investigate the adherence to NSBBs for the prevention of variceal bleeding in cirrhotic patients during their hospitalizations. The impact of adherence to NSBBs during follow-up on the development of variceal bleeding after discharge was also evaluated.

\section{Methods}

\section{Ethics}

This observational study was approved by the medical ethical committee of our hospital with an approval number [Number Y (2020) 004] and performed according to the Declaration of Helsinki.

\section{Study Design}

A total of 113 patients treated by one attending physician (XQ) from February 2018 to June 2019 were prospectively recorded and retrospectively screened and analyzed, as previously mentioned. ${ }^{24,25}$ The inclusion criteria were as follows: (1) a diagnosis of liver cirrhosis; and (2) an indication of NSBBs for primary or secondary prophylaxis of variceal bleeding during hospitalizations. Age, sex, etiology of liver cirrhosis, and hepatocellular carcinoma were not limited. Repeated admissions were not excluded.

\section{NSBBs}

Two clinical pharmacists (XX and YA) gave a premedication education to every patient who received NSBBs according to the current practice guidelines. ${ }^{5,6}$ In detail, NSBBs would be given, if the heart rate was $\geq 65$ beats per minute (b.p.m.) and blood pressures were $\geq 90 / 60$ $\mathrm{mmHg}$ before the use of NSBBs; ${ }^{6}$ NSBBs would not be given, if the heart rate was $<65$ b.p.m. and/or blood pressures were $<90 / 60 \mathrm{mmHg}$. The initial dosage of NSBBs was $10 \mathrm{mg}$ of propranolol (Jiangsu Yabang Epson Pharmaceutical Co., Ltd. National Pharmaceutical Standard H32020133) twice per day, and then an individualized dosage titration was based on the changes of heart rates and blood pressures during the use of NSBBs. In most cases, the dosage was increased or decreased by $5 \mathrm{mg}$ each time.

Two clinical pharmacists also recorded the use of NSBBs during the patients' hospitalizations carefully every day. Before the use of NSBBs, we recorded the patients' resting heart rates and blood pressures and causes for the intolerance to NSBBs. As for the patients who took NSBBs, we further recorded the dosage of NSBBs as well as the heart rates and blood pressures measured 30 minutes after the use of NSBBs. The changes of heart rates and blood pressures before and after the use of NSBBs were calculated for every patient.

There is no consensus or practice guideline specific to the adherence to NSBBs. In the present study, adherence to NSBBs was defined as the extent to which a patient took NSBBs as prescribed by the attending physician. ${ }^{26}$ Adherence to NSBBs was assessed on a daily basis. In detail, good adherence would be considered, if a patient took NSBBs exactly in accordance with the doctor's prescription and under the guidance of clinical pharmacists; on the contrary, if a patient forgot or refused to take NSBBs or monitor blood pressures and heart rates at least once, poor adherence would be considered. Hepatic venous pressure gradient measurement was not readily available at our hospital, so hemodynamic response was defined a reduction of resting heart rate $>20 \%$ from baseline or the resting heart rate reached 55-60 b.p.m. after the use of NSBBs during hospitalizations according to the current guideline. ${ }^{6}$

Adverse drug reactions during the use of NSBBs were recorded. According to the World Health Organization 
criteria, ${ }^{27}$ the grade of adverse drug reactions is divided as follows: 1) mild: a mild reaction or disease that usually does not require any treatment; 2) moderate: clinical symptoms are obvious and vital organs or systems are moderately damaged; and 3) severe: vital organs or systems are seriously damaged, resulting in disability and even deaths. The attending physician decided to stop NSBBs or decrease the dosage according to the severity of adverse drug reactions. Generally, mild adverse drug reactions do not cause discontinuation, and moderate and severe adverse drug reactions often lead to immediate discontinuation.

\section{Clinical Data Collection}

We collected the information regarding demographic data (ie, age and gender), etiology of liver disease, previous history of endoscopic variceal treatment and use of NSBBs, and laboratory tests. Child-Pugh and model for endstage liver disease (MELD: UNOS 2016 updated MELD including sodium) scores were calculated. The severity of esophageal varices was determined by upper gastrointestinal endoscopy. Primary or secondary prophylaxis of variceal bleeding was based on prior bleeding events. ${ }^{5}$

\section{Follow-Up}

Detailed information regarding use of NSBBs, bleeding events, and death after discharge were acquired by telephone follow-up and reviewing re-admission and outpatient medical records until July 2020. Good adherence to NSBBs during follow-up was defined as a patient had been taking long-term NSBBs regularly after discharge. Otherwise, poor adherence to NSBBs during follow-up would be considered, if a patient did not take NSBBs regularly or took NSBBs intermittently after discharge.

\section{Statistical Analyses}

Continuous variables were expressed as mean \pm standard deviation and median (range). Categorical variables were expressed as frequency (percentage). Nonparametric Mann-Whitney $U$-test was used for continuous variables and chi-square test was used for categorical variables. Paired $t$-test was used to compare the heart rates and blood pressures before and after the use of NSBBs. Logistic regression analyses were performed to identify the risk factors associated with poor adherence. Odds ratios (ORs) with 95\% confidence intervals (CIs) were calculated. All statistical analyses were performed with IBM SPSS software version 20.0 (SPSS Inc., Armonk, New York, USA) and
GraphPad Prism version 5.0 (GraphPad Software, Inc., La Jolla, California, USA). A two-sided $\mathrm{P}<0.05$ was considered statistically significant.

\section{Results \\ Patients}

During the study period, the data regarding adherence to NSBBs were not well recorded in 5 patients, because both of the two clinical pharmacists were on their holidays. Thus, a total of 108 cirrhotic patients were screened. Twelve patients were excluded. They were intolerant to NSBBs, because their heart rates were $<65$ b.p.m. and/or blood pressures were $<90 / 60 \mathrm{mmHg}$ at baseline. Finally, the adherence to NSBBs could be assessed in 96 patients (Figure 1).

Characteristics of patients at admission are shown in Table 1. The median age was 55.5 years (range: 28 to 88 ) and most patients were male (69/96, 71.9\%). Hepatitis B viral infection (46/96, 47.9\%) was the most common etiology of cirrhosis. A majority of patients had Child-Pugh class A+B (88/96, 91.7\%). The median MELD score was 9.98 (range: 6.65 to 26.39). Grade of esophageal varices could be evaluated in 85 patients by endoscopy during their hospitalizations, of whom 41, 13, and 31 had mild, moderate, and severe esophageal varices, respectively. Eighty-two patients had esophageal variceal bleeding before or at their admissions. Sixtythree patients had a history of endoscopic variceal treatment before their admissions. Fifty-two patients had a history of using NSBBs before their admissions. Most patients took propranolol, and only one patient took carvedilol. Fifteen patients were repeatedly admitted to our department (range: 2 to 4 times).

Three patients developed mild adverse drug reactions during the use of NSBBs, including headache, weakness, and sleep disturbance. Among them, two patients refused to continue the use of NSBBs, and one patient insisted on taking NSBBs. No patient developed moderate or severe adverse drug reactions.

\section{Adherence to NSBBs During Hospitalizations}

Among the 96 patients, 22 (22.9\%) had poor adherence to NSBBs due to their refusal to take NSBBs $(n=2)$, complete forgetfulness of NSBBs $(n=10)$, and refusal or forgetfulness to monitor heart rate and blood pressure $(n=10)$; and 74 (77.1\%) patients had good adherence to NSBBs. Dosage of NSBBs was titrated in 30 patients, of whom 24 had good 


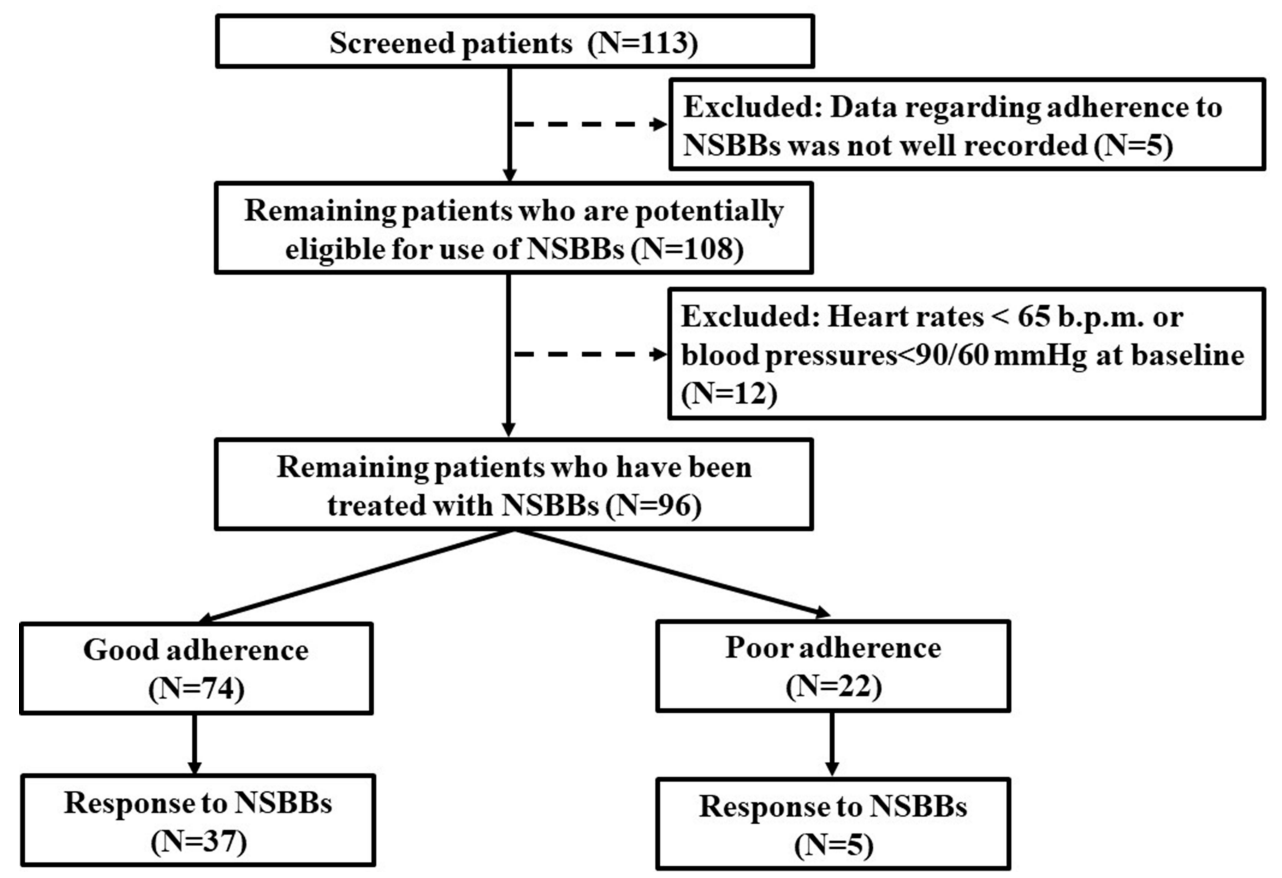

Figure I A flow chart of patient selection.

adherence and six had poor adherence. No dosage titration was performed in the remaining 66 patients.

Among the 74 patients with good adherence, 68 had Child-Pugh class $\mathrm{A}+\mathrm{B}$; the median MELD score was 9.87 (range: 7.08 to 22.06); grade of esophageal varices could be evaluated in 64 patients by endoscopy during their hospitalizations, of whom 30, 11, and 23 had mild, moderate, and severe esophageal varices, respectively; 65 patients had esophageal variceal bleeding before or at their admissions; 51 patients had a history of endoscopic variceal treatment before their admissions; 44 patients had a history of using NSBBs before their admissions; 25 patients took NSBBs continuously, and 49 took NSBBs with an interruption due to their decreased heart rates and/ or blood pressures.

\section{Changes in Heart Rate and Blood Pressures}

The average heart rate before and after using NSBBs was $74.84 \pm 10.00$ b.p.m. and $64.34 \pm 7.12$ b.p.m., respectively $(\mathrm{P}<0.001)$; and the average change of heart rate was -10.49 b.p.m. (95\% CI: -12.11 to -8.88$)$. In the good adherence group, the average heart rate before and after using NSBBs was $74.80 \pm 10.84$ b.p.m. and $63.93 \pm 7.44$ b.p.m., respectively $(\mathrm{P}<0.001)$; and the average change of heart rate was -10.87 b.p.m. ( $95 \%$ CI: -12.77 to -8.97$)$. In the poor adherence group, the average heart rate before and after using NSBBs was $75.00 \pm 4.97$ b.p.m. and $66.19 \pm 5.23$ b. p.m., respectively $(\mathrm{P}<0.001)$; and the average change of heart rate was -8.81 b.p.m. (95\% CI: -11.45 to -6.18 ) (Figure 2).

The average systolic blood pressure before and after using NSBBs was $123.44 \pm 12.07 \mathrm{mmHg}$ and $103.17 \pm$ $13.40 \mathrm{mmHg}$, respectively $(\mathrm{P}<0.001)$; and the average change of systolic blood pressure was $-20.27 \mathrm{mmHg}$ (95\% CI: -24.25 to -16.29 ). In the good adherence group, the average systolic blood pressure before and after using NSBBs was $122.26 \pm 17.47 \mathrm{mmHg}$ and $101.54 \pm 13.13 \mathrm{mmHg}$, respectively $(\mathrm{P}<0.001)$; and the average change of systolic blood pressure was -20.72 $\mathrm{mmHg}$ (95\% CI: -24.68 to -16.77$)$. In the poor adherence group, the average systolic blood pressure before and after using NSBBs was $128.25 \pm 24.64 \mathrm{mmHg}$ and $109.81 \pm$ $12.77 \mathrm{mmHg}$, respectively $(\mathrm{P}=0.010)$; and the average change of systolic blood pressure was $-18.44 \mathrm{mmHg}$ (95\% CI: -31.86 to -5.01 ) (Figure 3).

The average diastolic blood pressure before and after using NSBBs was $77.65 \pm 14.16 \mathrm{mmHg}$ and $66.94 \pm 11.30$ $\mathrm{mmHg}$, respectively $(\mathrm{P}<0.001)$; and the average change of diastolic blood pressure was $-10.72 \mathrm{mmHg}(95 \% \mathrm{CI}:-13.69$ to -7.75). In the good adherence group, the average diastolic blood pressure before and after using NSBBs was $76.86 \pm$ $13.30 \mathrm{mmHg}$ and $65.37 \pm 11.16 \mathrm{mmHg}$, respectively $(\mathrm{P}<0.001)$; and the average change of diastolic blood 
Table I Patients' Characteristics

\begin{tabular}{|c|c|c|}
\hline Variables & No. Pts & Overall \\
\hline Age (years) & 96 & $\begin{array}{l}55.50(28.00-88.00) \\
55.72 \pm 12.25\end{array}$ \\
\hline Male (\%) & 96 & 69 (71.90\%) \\
\hline \multicolumn{3}{|l|}{ Etiology of liver diseases } \\
\hline Hepatitis B virus (\%) & 96 & 46 (47.90\%) \\
\hline Hepatitis C virus (\%) & 96 & $10(10.40 \%)$ \\
\hline Alcohol abuse (\%) & 96 & $25(26.00 \%)$ \\
\hline Autoimmune liver diseases (\%) & 96 & 7 (7.30\%) \\
\hline History of endoscopic variceal treatment (\%) & 96 & $63(65.60 \%)$ \\
\hline History of using NSBBs (\%) & 96 & $52(54.20 \%)$ \\
\hline \multicolumn{3}{|l|}{ Laboratory tests } \\
\hline Red blood cell $\left(10^{12} / \mathrm{L}\right)$ & 96 & $\begin{array}{l}3.40(1.96-5.07) \\
3.46 \pm 0.81\end{array}$ \\
\hline Hemoglobin $(\mathrm{g} / \mathrm{L})$ & 96 & $\begin{array}{l}103.00(47.00-155.00) \\
101.38 \pm 27.44\end{array}$ \\
\hline White blood cell $\left(10^{9} / \mathrm{L}\right)$ & 96 & $\begin{array}{l}3.60(1.00-20.10) \\
4.23 \pm 2.60\end{array}$ \\
\hline Platelet $\left(10^{9} / \mathrm{L}\right)$ & 96 & $\begin{array}{l}76.50(19.00-470.00) \\
99.63 \pm 78.72\end{array}$ \\
\hline Total bilirubin $(\mu \mathrm{mol} / \mathrm{L})$ & 96 & $\begin{array}{l}20.70(5.60-119.30) \\
25.08 \pm 19.05\end{array}$ \\
\hline Direct bilirubin $(\mu \mathrm{mol} / \mathrm{L})$ & 96 & $\begin{array}{l}8.70(1.90-81.80) \\
\mid 1.77 \pm 11.00\end{array}$ \\
\hline Albumin $(g / L)$ & 96 & $\begin{array}{l}31.89(21.30-50.60) \\
33.19 \pm 6.48\end{array}$ \\
\hline Alanine aminotransferase $(U / L)$ & 96 & $\begin{array}{l}24.15(4.47-152.11) \\
29.15 \pm 22.02\end{array}$ \\
\hline Aspartate aminotransferase (U/L) & 96 & $\begin{array}{l}31.61(9.92-202.40) \\
4.53 \pm 30.40\end{array}$ \\
\hline Alkaline phosphatase (U/L) & 96 & $\begin{array}{l}92.98(27.98-983.93) \\
130.46 \pm \mid 61.00\end{array}$ \\
\hline Gamma-glutamyl transpeptidase (U/L) & 96 & $\begin{array}{l}44.69(8.23-1227.00) \\
83.85 \pm 142.45\end{array}$ \\
\hline Blood urea nitrogen (mmol/L) & 96 & $\begin{array}{l}5.30(1.86-14.68) \\
5.89 \pm 2.73\end{array}$ \\
\hline Serum creatinine $(\mu \mathrm{mol} / \mathrm{L})$ & 96 & $\begin{array}{l}64.77(32.65-178.55) \\
66.60 \pm 20.40\end{array}$ \\
\hline Potassium (mmol/L) & 96 & $\begin{array}{l}3.92(2.42-5.45) \\
3.90 \pm 0.47\end{array}$ \\
\hline Sodium (mmol/L) & 96 & $\begin{array}{l}\mid 39.00(|| 8.00-\mid 47.70) \\
\mid 38.23 \pm 3.59\end{array}$ \\
\hline Prothrombin time (seconds) & 96 & $\begin{array}{l}16.00(12.10-23.10) \\
16.26 \pm 2.30\end{array}$ \\
\hline INR & 96 & $\begin{array}{l}1.30(0.90-2.04) \\
1.32 \pm 0.23\end{array}$ \\
\hline
\end{tabular}


Table I (Continued).

\begin{tabular}{|l|l|l|}
\hline Variables & No. Pts & Overall \\
\hline Child-Pugh score & 96 & $\begin{array}{l}6.50(5.00-11.00) \\
6.81 \pm 1.59\end{array}$ \\
\hline Child-Pugh class A/B/C (\%) & 96 & $48(50.00 \%) / 40(41.70 \%) / 8$ \\
& $(8.30 \%)$ \\
\hline MELD score & 96 & $9.98(6.65-26.39)$ \\
& & $11.09 \pm 3.69$ \\
\hline Primary prophylaxis (\%) & 96 & $14(14.60 \%)$ \\
Secondary prophylaxis (\%) & 96 & $82(85.40 \%)$ \\
Good adherence to NSBBs (\%) & 96 & $74(77.10 \%)$ \\
Response to NSBBs (\%) & 96 & $42(43.80 \%)$ \\
Dosage titration (\%) & 96 & $30(31.30 \%)$ \\
\hline
\end{tabular}

Abbreviations: Pts, patients; INR, international normalized ratio; MELD, model for end-stage liver disease; NSBBs, non-selective beta blockers.

pressure was $-11.49 \mathrm{mmHg}$ (95\% CI: -14.58 to -8.45$)$. In the poor adherence group, the average diastolic blood pressure before and after using NSBBs was $80.00 \pm 17.33 \mathrm{mmHg}$ and $73.31 \pm 9.78 \mathrm{mmHg}$, respectively $(\mathrm{P}=0.093)$; and the average change of diastolic blood pressure was $-7.56 \mathrm{mmHg}$ (95\% CI: -16.53 to 1.41) (Figure 4).

There was no statistically significant difference in dynamic changes of heart rates and blood pressures before and after the use of NSBBs between good and poor adherence groups (Figure 5).

\section{Response to NSBBs}

In the good adherence group, 17 patients had a reduction of resting heart rate $>20 \%$ from baseline, 24 patients' resting heart rate was reduced to 55-60 b.p.m., and four patients met both criteria. Thus, $37(50.0 \%)$ patients responded to NSBBs, of whom 13 had dosage titration.

In the poor adherence group, two patients had a reduction of resting heart rate $>20 \%$ from baseline, four patients' resting heart rate was reduced to $55-60$ b.p.m., and one patient met both criteria. Thus, five (22.7\%) patients responded to NSBBs, of whom two had dosage titration.

There was a statistically significant difference in the rate of response to NSBBs between good and poor adherence groups $(50.0 \%$ [37/74] versus $22.7 \%$ [5/22], $\mathrm{P}=0.024)$.

\section{Factors Related to Poor Adherence to NSBBs}

The univariate logistic regression analysis indicated that only older age was significantly associated with poor adherence (OR: $1.065,95 \%$ CI: $1.019-1.114, \mathrm{P}=0.005$ ) (Table 2).

\section{Adherence to NSBBs During Follow-Up}

We could effectively contact with 92 patients about their follow-up information, but four patients were lost. Among the 92 patients, 15 died without any further information regarding use of NSBBs. Thus, the remaining 77 survived patients could be evaluated for adherence to NSBBs during a median follow-up duration of 20 months (range: 12 to 29). Among them, 12 patients developed esophageal variceal bleeding events after discharge; 41 patients had good adherence during follow-up, 25 had poor adherence, and 11 were intolerant. Patients with poor adherence during follow-up had a significantly higher incidence of esophageal variceal bleeding after discharge than those with good adherence $(32.0 \%$ [8/25] versus $9.8 \%$ [4/41], $\mathrm{P}=0.023$ ).

Among the 41 patients with Child-Pugh class A, 23 had good adherence during follow-up, 10 had poor adherence, and eight were intolerant. The incidence of esophageal variceal bleeding after discharge was not significantly different between patients with poor and good adherence (30.0\% [3/10] versus $8.7 \%$ [2/23], $\mathrm{P}=0.117)$. Among the 36 patients with Child-Pugh class B/C, 18 had good adherence during follow-up, 15 had poor adherence, and three were intolerant. The incidence of esophageal variceal bleeding after discharge was not significantly different between patients with poor and good adherence $(33.3 \%$ [5/15] versus $11.1 \%$ [2/18], $\mathrm{P}=0.120)$. 


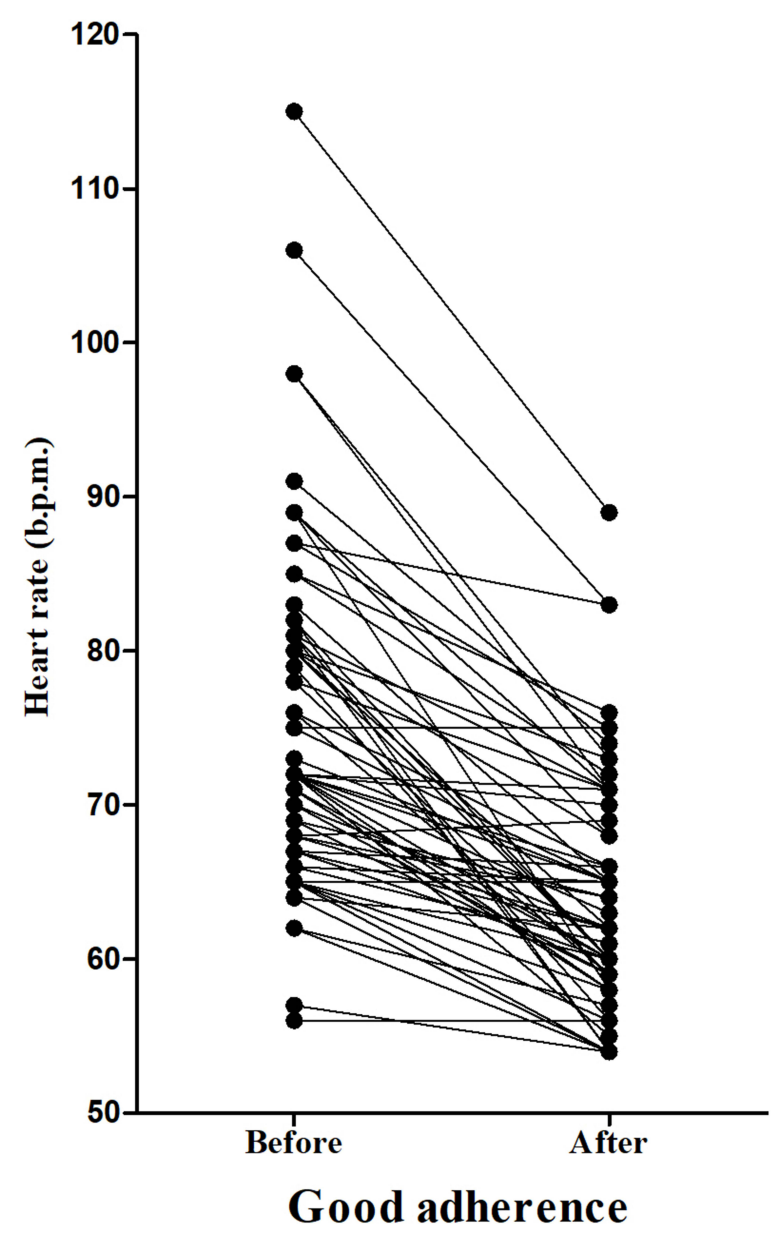

Figure 2 Changes of heart rate before and after the use of NSBBs.

Among the 11 patients without esophageal variceal bleeding before or at their admissions, seven had good adherence during follow-up, two had poor adherence, and two were intolerant. The incidence of esophageal variceal bleeding after discharge was not significantly different between patients with poor and good adherence $(0.0 \%$ [0/2] versus $14.3 \%$ [1/7], $\mathrm{P}=0.778$ ). Among the 66 patients with esophageal variceal bleeding before or at their admissions, 34 had good adherence during follow-up, 23 had poor adherence, and nine were intolerant. Patients with poor adherence during follow-up had a significantly higher incidence of esophageal variceal rebleeding after discharge than those with good adherence (34.8\% [8/23] versus $8.8 \%$ [3/34], $\mathrm{P}=0.015)$.

Among the 39 patients with mild/moderate esophageal varices, 21 had good adherence during follow-up, 13 had poor adherence, and five were intolerant. The incidence of esophageal variceal bleeding after discharge was not significantly different between patients with poor and good adherence (30.8\% [4/13] versus

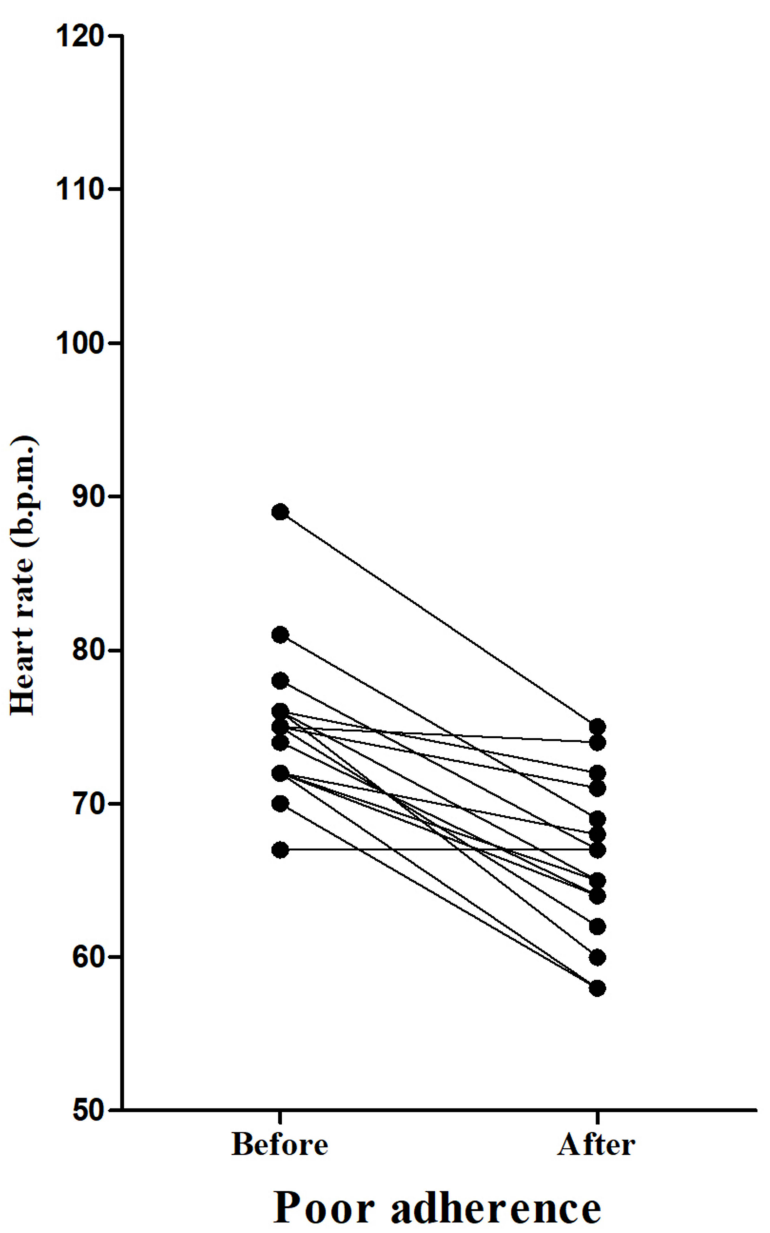

9.2\% [2/21], $\mathrm{P}=0.114)$. Among the 34 patients with severe esophageal varices, 18 had good adherence during follow-up, 10 had poor adherence, and six were intolerant. The incidence of esophageal variceal bleeding after discharge was not significantly different between patients with poor and good adherence $(40.0 \%$ [4/10] versus $11.1 \%[2 / 18], \mathrm{P}=0.074)$.

\section{Discussion}

This study had several major findings, as follows: 1) not all patients were suitable for the use of NSBBs due to low heart rates and/or blood pressures at baseline; 2) a substantial proportion of cirrhotic patients had poor adherence to NSBBs during their hospitalizations; 3) patients with poor adherence had a significantly lower response rate; 4) older age was associated with poor adherence during hospitalization; and 5) patients with poor adherence during follow-up were more likely to develop bleeding events. 


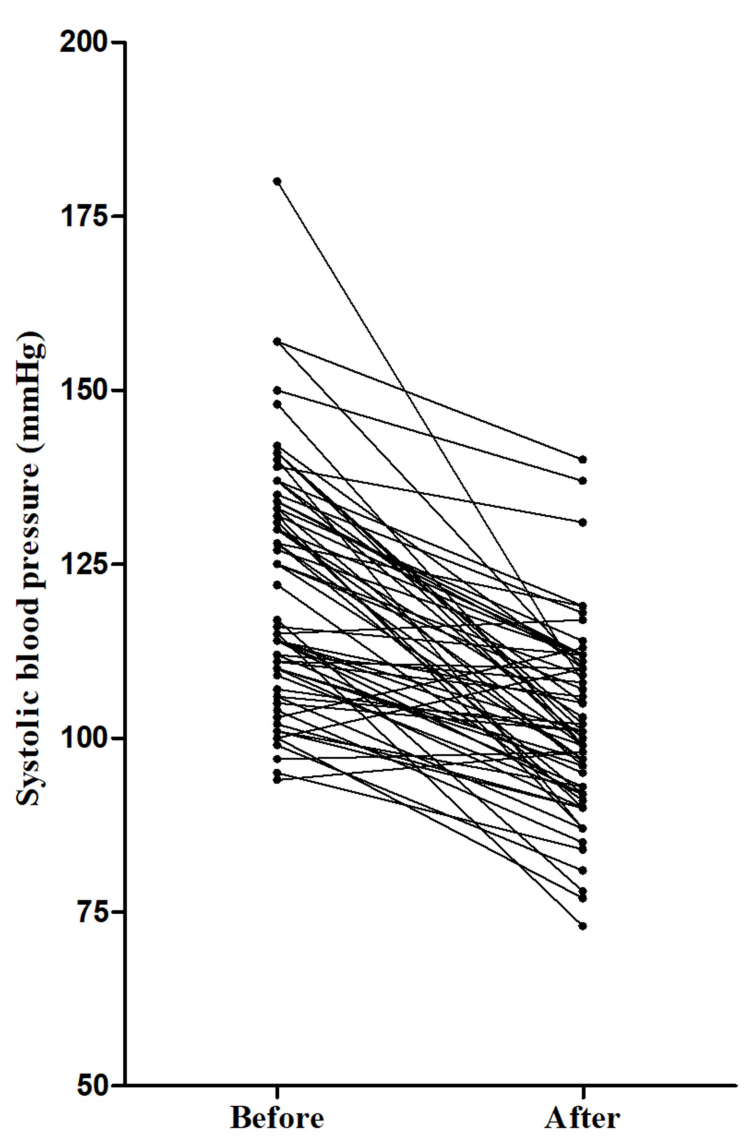

Good adherence

Figure 3 Changes of systolic blood pressure before and after the use of NSBBs.

Poor adherence may increase both morbidity and mortality. ${ }^{28-30}$ According to the World Health Organization, an increase in the adherence may have a much greater impact on population health than any improvement in specific medical treatments. ${ }^{26}$ Patients with liver cirrhosis should regularly and chronically take NSBBs to prevent from esophageal variceal bleeding. ${ }^{31}$ Long-term use of NSBBs can also reduce the 6-month mortality. ${ }^{32}$ In addition, good adherence to NSBBs can improve the health-related quality of life in cirrhotic patients; ${ }^{33}$ by contrast, missed medication was associated with a higher risk of recurrence of cirrhosis-related symptoms. $^{34,35}$ In the real-world clinical practice, not all cirrhotic patients who have indications for NSBBs according to the clinical guidelines have taken NSBBs. ${ }^{36}$ Maddur et al reported that $29 \%$ of patients requiring the primary prophylaxis of variceal bleeding received NSBBs, and that $36 \%$ of patients requiring the secondary prophylaxis of variceal bleeding received NSBBs. ${ }^{37}$ Everett et al found that $87 \%$ of patients requiring the prophylaxis of variceal rebleeding after discharge

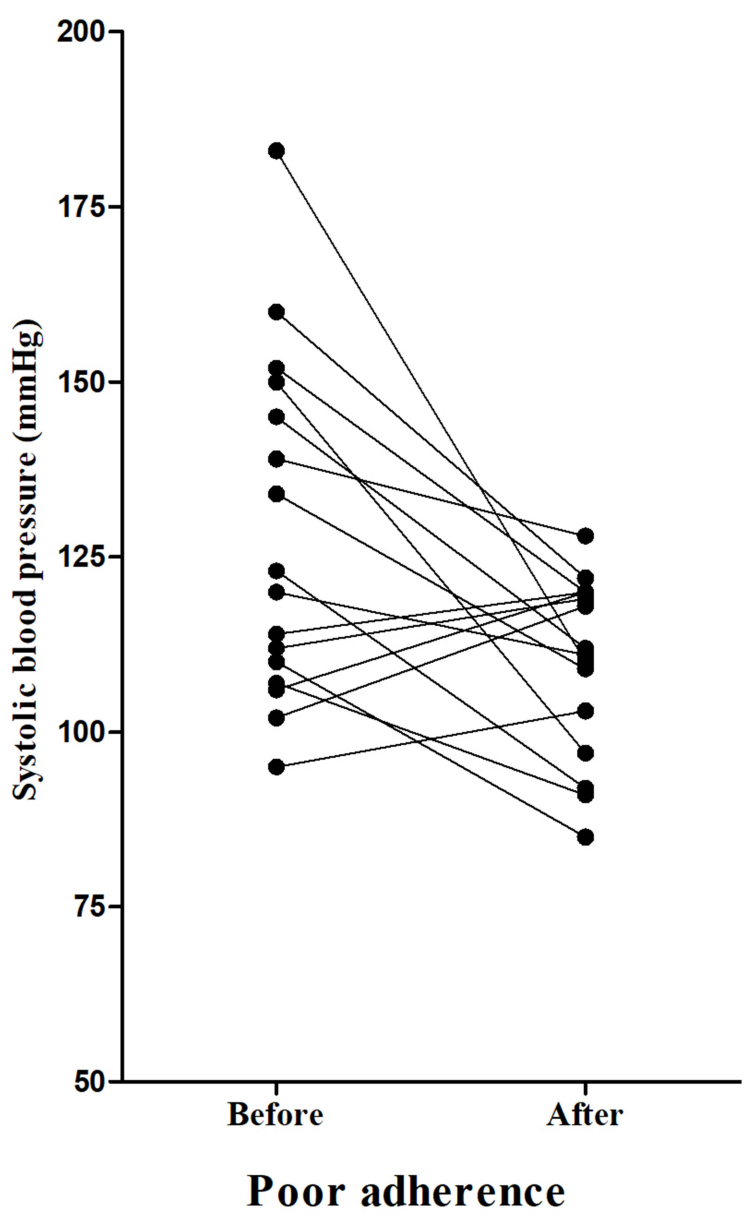

were treated with NSBBs. ${ }^{23}$ Our study showed that $23 \%$ of our patients had poor adherence during their hospitalizations. But it should be noted that our definition is relatively strict, which may overestimate the rate of poor adherence. Collectively, these data suggested that adherence to NSBBs deserves more attention and should be further improved.

Adherence to medical treatment for chronic patients is challenging. There are many causes for poor adherence, such as social, economic, health system-related, diseaserelated, patient-related, and therapy-related. ${ }^{26,38}$ Similarly, the individuals' behavioral factors, drug-related adverse reactions, and changing doses by monitoring heart rates and blood pressures may be associated with poor adherence to NSBBs. ${ }^{31}$ Our patients had some subjective factors associated with poor adherence, such as refusal or forgetfulness. Additionally, poor adherence might be related to a strong suspicion to medications. ${ }^{39,40}$ Patients often considered treatment and prevention as two completely different entities. Among the patients requiring the primary 


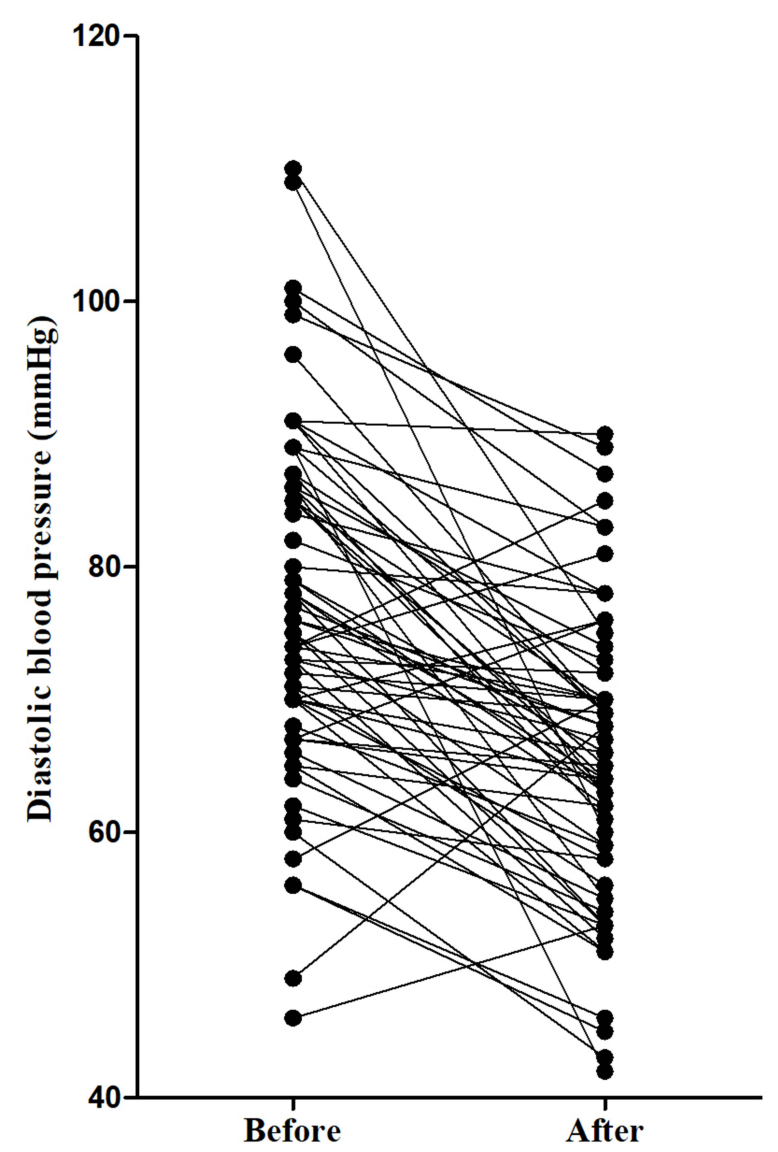

Good adherence

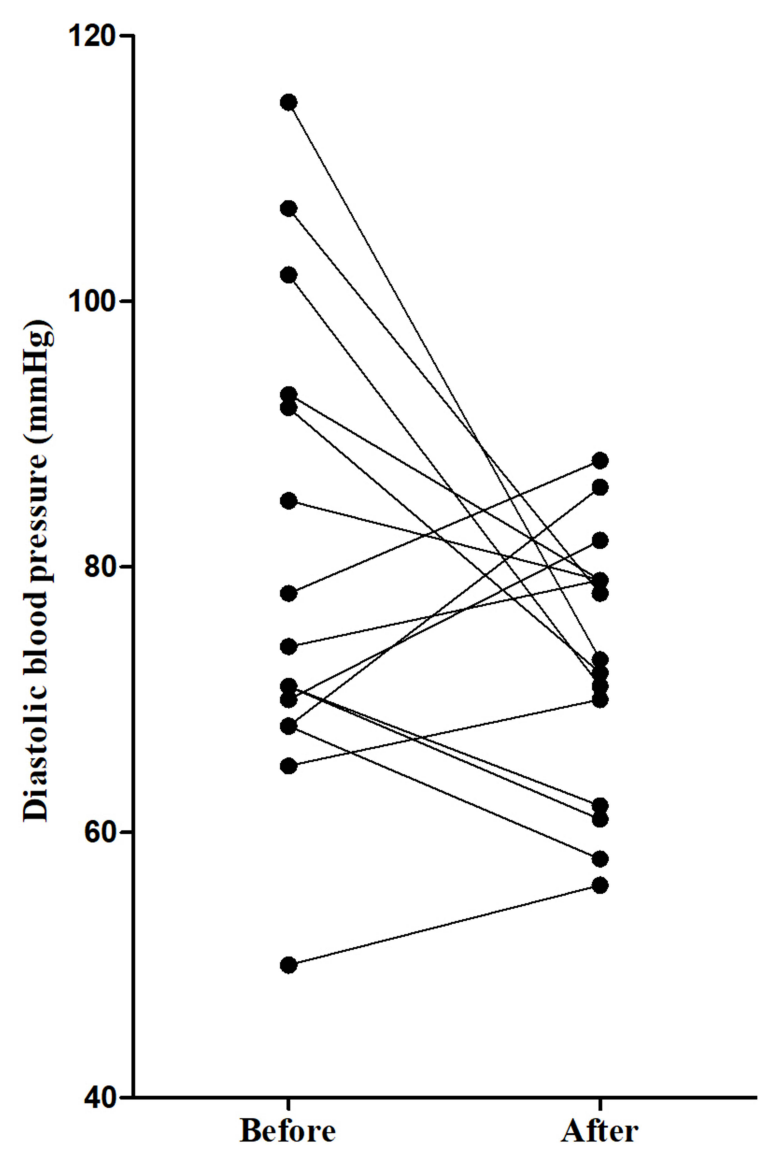

Poor adherence

Figure 4 Changes of diastolic blood pressure before and after the use of NSBBs.
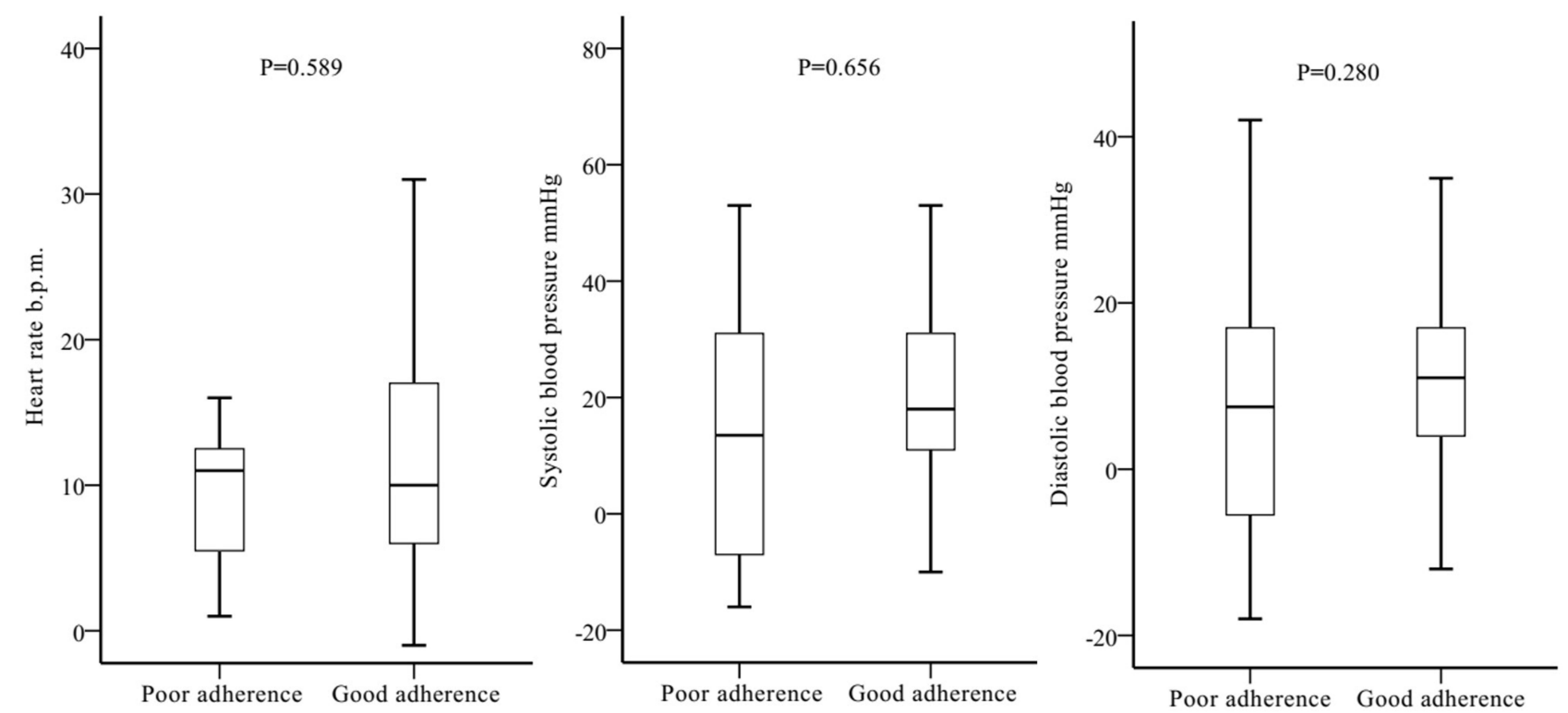

Figure 5 Changes of heart rate and blood pressures before and after the use of NSBBs between the two groups. 
Table 2 Univariate Logistic Regression Analysis of Variables Related to Poor Adherence

\begin{tabular}{|c|c|c|c|c|c|c|}
\hline \multirow[t]{2}{*}{ Variables } & \multirow{2}{*}{$\begin{array}{l}\text { No. } \\
\text { Pts }\end{array}$} & \multirow{2}{*}{$\begin{array}{c}\text { Poor } \\
\text { Adherence }\end{array}$} & \multirow{2}{*}{$\begin{array}{c}\text { Good } \\
\text { Adherence }\end{array}$} & \multicolumn{3}{|c|}{ Univariate Logistic Regression } \\
\hline & & & & OR & $95 \% \mathrm{Cl}$ & $P$ value \\
\hline Age (years) & 96 & $62.4 \mid \pm 13.03$ & $53.73 \pm 11.36$ & 1.065 & $1.019-1.114$ & 0.005 \\
\hline Male & 96 & $18 / 22(81.80 \%)$ & $5 \mathrm{I} / 74(68.90 \%)$ & 2.029 & $0.6|7-6.67|$ & 0.244 \\
\hline \multicolumn{7}{|l|}{ Etiology of liver diseases } \\
\hline Hepatitis $B$ virus & 96 & $12 / 22(54.50 \%)$ & $34 / 74(45.90 \%)$ & 1.569 & $0.590-4.170$ & 0.367 \\
\hline Hepatitis $C$ virus & 96 & $2 / 22(9.10 \%)$ & $8 / 74(10.80 \%)$ & 0.868 & $0.170-4.438$ & 0.865 \\
\hline Alcohol abuse & 96 & $6 / 22(27.30 \%)$ & $19 / 74(25.70 \%)$ & 1.158 & $0.393-3.413$ & 0.790 \\
\hline Autoimmune liver diseases & 96 & $\mathrm{I} / 22(4.50 \%)$ & $6 / 74(8.10 \%)$ & 0.567 & $0.064-4.987$ & 0.609 \\
\hline History of endoscopic variceal treatment & 96 & $12 / 22(54.50 \%)$ & $5 \mathrm{I} / 74(68.90 \%)$ & 0.541 & $0.205-1.432$ & 0.216 \\
\hline History of using NSBBs & 96 & $8 / 22(36.40 \%)$ & $44 / 74(49.50 \%)$ & 0.390 & $0.146-1.043$ & 0.061 \\
\hline Child-Pugh score & 96 & $7.18 \pm 1.62$ & $6.70 \pm 1.58$ & 1.202 & $0.898-1.609$ & 0.207 \\
\hline MELD score & 96 & || $.4 \mid \pm 4.64$ & $10.99 \pm 3.39$ & 1.023 & $0.902-I .16 I$ & 0.720 \\
\hline Primary prophylaxis & 96 & $5 / 22(22.70 \%)$ & $9 / 74(12.20 \%)$ & 2.124 & $0.629-7.17 \mid$ & 0.225 \\
\hline Secondary prophylaxis & 96 & I7/22 (77.30\%) & $65 / 74(87.80 \%)$ & 0.471 & $0.139-1.589$ & 0.225 \\
\hline
\end{tabular}

Note: The value in bold is defined as being statistically significant.

Abbreviations: Pts, patients; OR, odds ratio; Cl, confidence interval; NSBBs, non-selective beta blockers; MELD, model for end-stage liver disease.

prophylaxis, adherence to "useful treatment" may be relatively poor since its clinical benefits are not yet immediate and apparent. ${ }^{39}$ Some of our patients requiring the primary prophylaxis (ie, patients without a history of variceal bleeding) did not fully understand the effect of prophylactic interventions, and even suspected the role of NSBBs, which would lead to poor adherence. In fact, our study suggested that the adherence seemed to be poorer among the patients without a history of using NSBBs, because they may be less acquainted with the role and clinical effects of NSBBs. However, this difference was not statistically significant. Finally, another cause of poor adherence may be that patients were often lacking of their awareness of disease. ${ }^{41}$ Only half of cirrhotic patients understood their diseases, while most of them reported a difficulty in understanding medical information. ${ }^{42}$

Medical workers should actively strengthen the adherence interventions to increase the efficacy of drug treatment. ${ }^{39}$ Main interventions include behavioral intervention, educational intervention, integrated care intervention, self-management, risk communication, and packaging and daily reminders. ${ }^{18}$ In detail, the methods for improving the adherence may include 1) strengthening the communication between doctors or clinical pharmacists and patients, especially elderly patients; 2 ) increasing the patients' confidence in medications, especially in patients who have not taken NSBBs; 3) performing psychological therapy; 4) conducting telephone follow-up; and 5) using electronic medication packaging devices, smart pillboxes, and mobile application to remind of taking medication to improve adherence. ${ }^{39,43-45}$ Additionally, the patients' heart rates and blood pressures before and after taking medication can be recorded by using a smart health bracelet and its corresponding mobile application.

Our study has some features. First, all patients included were inpatients to ensure the accuracy and reliability of data during their hospitalizations. However, due to the absence of everyday face-to-face communications with outpatients, it is difficult to monitor the accuracy of the data regarding how to take NSBBs. Second, all patients were treated by one attending physician with the same treatment strategy. Third, the use of NSBBs for all patients during their hospitalizations was carefully followed on a daily basis by two clinical pharmacists. Finally, a majority of our patients took a relatively low dosage of NSBBs, which might be safer and more tolerated. ${ }^{46}$ Simultaneously, several limitations should be acknowledged. First, the sample size was small and might be unpowered. Second, more factors that may affect the patient's adherence to NSBBs, such as number of 
combined medications, whether the patient was accompanied by a family member or caregiver, and whether the patient had a memory loss, should be extensively explored in future. Third, hepatic venous pressure gradient was not measured before and after using NSBBs. Fourth, varices at other locations, such as para and perioesophageal varices, were not evaluated. Finally, the use of NSBBs depended upon the patients' self-reports, despite our clinical pharmacists visited all patients every day.

In conclusion, our study demonstrated that a significant proportion of patients with liver cirrhosis had poor adherence to NSBBs. In view of potential hazards caused by poor adherence, we should improve the adherence to NSBBs through patient self-education, doctor-driven patient education, and enhanced case management, such as drug blister packs and smartphone applications. In future, well-designed clinical trials are needed to explore how to improve the patient's adherence to NSBBs, and to clarify the impact of improved adherence on clinical outcomes.

\section{Abbreviations}

NSBBs, non-selective beta blockers; b.p.m., beats per minute; MELD, model for end-stage liver disease; OR, odds ratios; CI, confidence intervals.

\section{Data Sharing Statement}

The datasets generated during and/or analyzed during the current study are available from the corresponding author on reasonable request.

\section{Acknowledgments}

We would like to appreciate our study team, including Wenchun Bao, Feifei Hou, Zeqi Guo, Jingqiao Zhang, Xinmiao Zhou, Miaomiao Li, Ruirui Feng, Cen Hong, Yanglan $\mathrm{He}$, Shixue $\mathrm{Xu}$, and Yang $\mathrm{An}$, of whom all had worked for our study group of establishing and updating this database, which prospectively recorded the patients treated by Dr. Xingshun Qi.

The paper has been partially presented as a poster in the Asian Pacific Association for the Study of the Liver (APASL) 2021 conference Hepatol Int (2021) 15 (Suppl. 1):S1-S104. https://doi.org/10.1007/s12072-021-10213-7. Yang An, Xiangbo Xu, Tianshu Ren, and Zhenhua Tong are co-first authors for this study.

\section{Funding}

No funding or sponsorship was received for this study or publication of this article.

\section{Disclosure}

The authors declare that there is no conflict of interest in this study.

\section{References}

1. de Franchis R, Primignani M. Natural history of portal hypertension in patients with cirrhosis. Clin Liver Dis. 2001;5(3):645-663. doi:10.1016/S1089-3261(05)70186-0

2. Li Y, Li H, Zhu Q, et al. Effect of acute upper gastrointestinal bleeding manifestations at admission on the in-hospital outcomes of liver cirrhosis: hematemesis versus melena without hematemesis. Eur $J$ Gastroenterol Hepatol. 2019;31(11):1334-1341. doi:10.1097/ MEG.0000000000001524

3. Garcia-Tsao G, Bosch J. Management of varices and variceal hemorrhage in cirrhosis. N Engl J Med. 2010;362(9):823-832. doi:10.1056/ NEJMra0901512

4. Bari K, Garcia-Tsao G. Treatment of portal hypertension. World J Gastroenterol. 2012;18(11):1166-1175. doi:10.3748/wjg.v18.i11.1166

5. de Franchis R. Expanding consensus in portal hypertension: report of the Baveno VI Consensus Workshop: stratifying risk and individualizing care for portal hypertension. J Hepatol. 2015;63(3):743-752. doi:10.1016/j.jhep.2015.05.022

6. Garcia-Tsao G, Abraldes JG, Berzigotti A, Bosch J. Portal hypertensive bleeding in cirrhosis: risk stratification, diagnosis, and management: 2016 practice guidance by the American Association for the study of liver diseases. Hepatology. 2017;65(1):310-335. doi:10.1002/hep.28906

7. Tripathi D, Stanley AJ, Hayes PC, et al. U.K. guidelines on the management of variceal haemorrhage in cirrhotic patients. Gut. 2015;64(11):1680-1704. doi:10.1136/gutjnl-2015-309262

8. European Association for the Study of the Liver. EASL Clinical Practice Guidelines for the management of patients with decompensated cirrhosis. J Hepatol. 2018;69(2):406-460. doi:10.1016/j. jhep.2018.03.024

9. Bultas AC, Teshome B, Richter SK, Schafers S, Cooke E, Call WB Use of nonselective beta-blockers in patients with end-stage liver disease and select complications. Ann Pharmacother. 2019;54:1060028019893092. doi:10.1177/1060028019893092

10. D'Amico G, Pagliaro L, Bosch J. The treatment of portal hypertension: a meta-analytic review. Hepatology. 1995;22(1):332-354. doi:10.1002/hep. 1840220145

11. Brett BT, Hayes PC, Jalan R. Primary prophylaxis of variceal bleeding in cirrhosis. Eur J Gastroenterol Hepatol. 2001;13(4):349-358. doi:10.1097/00042737-200104000-00008

12. Bernard B, Lebrec D, Mathurin P, Opolon P, Poynard T. Betaadrenergic antagonists in the prevention of gastrointestinal rebleeding in patients with cirrhosis: a meta-analysis. Hepatology. 1997;25 (1):63-70. doi:10.1002/hep.510250112

13. Tripathi D, Hayes PC. Beta-blockers in portal hypertension: new developments and controversies. Liver Int. 2014;34(5):655-667. doi:10.1111/liv.12360

14. Vorobioff J, Picabea E, Villavicencio R, et al. Acute and chronic hemodynamic effects of propranolol in unselected cirrhotic patients. Hepatology. 1987;7(4):648-653. doi:10.1002/ hep. 1840070406

15. Hernandez-Gea V, Aracil C, Colomo A, et al. Development of ascites in compensated cirrhosis with severe portal hypertension treated with beta-blockers. Am J Gastroenterol. 2012;107(3):418-427. doi:10.1038/ajg.2011.456

16. Senzolo M, Cholongitas E, Burra P, et al. Beta-blockers protect against spontaneous bacterial peritonitis in cirrhotic patients: a meta-analysis. Liver Int. 2009;29(8):1189-1193. doi:10.1111/j.14783231.2009.02038.x 
17. Northup PG, Henry ZH. Editorial: beta-blockers and the prevention of decompensation in cirrhosis: worth the trouble. $\mathrm{Am}$ J Gastroenterol. 2012;107(3):428-430. doi:10.1038/ajg.2011.466

18. Costa E, Giardini A, Savin M, et al. Interventional tools to improve medication adherence: review of literature. Patient Prefer Adherence. 2015;9:1303-1314. doi:10.2147/PPA.S87551

19. Lam WY, Fresco P. Medication adherence measures: an overview. Biomed Res Int. 2015;2015:217047. doi:10.1155/2015/217047

20. Kones R, Rumana U, Morales-Salinas A. Confronting the most challenging risk factor: non-adherence. Lancet (London, England). 2019;393(10167):105-106. doi:10.1016/S0140-6736(18)33079-4

21. Snyder S, Crandell I, Davis SA, Feldman SR. Medical adherence to acne therapy: a systematic review. Am J Clin Dermatol. 2014;15 (2):87-94. doi:10.1007/s40257-014-0063-y

22. Herttua K, Martikainen P, Batty GD, Kivimäki M. Poor adherence to statin and antihypertensive therapies as risk factors for fatal stroke. $J$ Am Coll Cardiol. 2016;67(13):1507-1515. doi:10.1016/j. jacc.2016.01.044

23. Everett BT, Lidofsky SD. Adherence to surveillance endoscopy following hospitalization for index esophageal variceal hemorrhage. World $J$ Gastrointest Surg. 2018;10(4):40-48. doi:10.4240/wjgs.v10.i4.40

24. Hong C, Xu X, Feng R, et al. Use of iron sucrose injection in anemia patients with reduced serum iron concentration during hospitalizations of digestive and liver diseases. Ann Palliat Med. 2021;10 (2):1145-1153. doi:10.21037/apm-19-499

25. Li M, Guo Z, Zhang D, et al. Correlation of serum cardiac markers with acute decompensating events in liver cirrhosis. Gastroenterol Res Pract. 2020;2020:4019289. doi:10.1155/2020/4019289

26. De Geest S, Sabate E. Adherence to long-term therapies: evidence for action, World Health Organization, Geneva, Switzerland, 2003. Eur $J$ Cardiovasc Nurs. 2003;2(4):323. doi:10.1016/S1474-5151(03) 00091-4

27. Edwards IR, Aronson JK. Adverse drug reactions: definitions, diagnosis, and management. Lancet (London, England). 2000;356 (9237):1255-1259. doi:10.1016/S0140-6736(00)02799-9

28. Polonsky WH, Henry RR. Poor medication adherence in type 2 diabetes: recognizing the scope of the problem and its key contributors. Patient Prefer Adherence. 2016;10:1299-1307. doi:10.2147/PPA.S106821

29. Xu T, Yu X, Ou S, Liu X, Yuan J, Chen Y. Statin adherence and the risk of stroke: a dose-response meta-analysis. CNS Drugs. 2017;31 (4):263-271. doi:10.1007/s40263-017-0420-5

30. Simpson SH, Eurich DT, Majumdar SR, et al. A meta-analysis of the association between adherence to drug therapy and mortality. $B M J$. 2006;333(7557):15. doi:10.1136/bmj.38875.675486.55

31. Xu X, Guo X, Tacke F, Shao X, Qi X. Use of nonselective $\beta$ blockers after variceal eradication in cirrhotic patients undergoing secondary prophylaxis of esophageal variceal bleeding: a critical review of current evidence. Ther Adv Chronic Dis. 2019;10:2040622319862693. doi:10.1177/2040622319862693

32. Pfisterer N, Dexheimer C, Fuchs EM, et al. Betablockers do not increase efficacy of band ligation in primary prophylaxis but they improve survival in secondary prophylaxis of variceal bleeding. Aliment Pharmacol Ther. 2018;47(7):966-979. doi:10.1111/apt.14485
33. Burge S, White D, Bajorek E, et al. Correlates of medication knowledge and adherence: findings from the residency research network of South Texas. Fam Med. 2005;37(10):712-718.

34. Debernardi Venon W, Elia C, Stradella D, et al. Prospective randomized trial: endoscopic follow up 3 vs 6 months after esophageal variceal eradication by band ligation in cirrhosis. Eur J Intern Med. 2014;25(7):674-679. doi:10.1016/j.ejim.2014.06.013

35. Polis S, Zang L, Mainali B, et al. Factors associated with medication adherence in patients living with cirrhosis. J Clin Nurs. 2016;25(12):204-212. doi:10.1111/jocn.13083

36. Hayward KL, Valery PC, Cottrell WN, et al. Prevalence of medication discrepancies in patients with cirrhosis: a pilot study. $B M C$ Gastroenterol. 2016;16(1):114. doi:10.1186/s12876-016-0530-4

37. Maddur H, Naik S, Siddiqui AA, Rockey DC. Adherence and adequacy of therapy for esophageal varices prophylaxis. Dig Dis Sci. 2011;56(11):3129-3136. doi:10.1007/s10620-011-1749-0

38. Brown MT, Bussell JK. Medication adherence: WHO cares? Mayo Clin Proc. 2011;86(4):304-314. doi:10.4065/mcp.2010.0575

39. Hayward KL, Valery PC, Martin JH, et al. Medication beliefs predict medication adherence in ambulatory patients with decompensated cirrhosis. World J Gastroenterol. 2017;23(40):7321-7331. doi:10.3748/wjg.v23.i40.7321

40. Sovaila S, Purcarea A, Gheonea D, Ciurea T. Specific factors that influence adherence to beta blocker treatment in primary prevention of variceal bleeding in cirrhotic Romanian patients. A proof of concept qualitative study. $J$ Med Life. 2018;11(4):355-358. doi:10.25122/jml-2018-1006

41. Kucukarslan SN. A review of published studies of patients' illness perceptions and medication adherence: lessons learned and future directions. RSAP. 2012;8(5):371-382. doi:10.1016/j.sapharm.20 11.09.002

42. Hayward KL, Horsfall LU. Optimising care of patients with chronic disease: patient-oriented education may improve disease knowledge and self-management. Intern Med J. 2017;47(8):952-955. doi:10.1111/imj. 13505

43. Haynes RB, Ackloo E, Sahota N, McDonald HP, Yao X. Interventions for enhancing medication adherence. Cochrane Database Syst Rev. 2008;(2):Cd000011. doi:10.1002/14651858. CD000011.pub3

44. Zolnierek KB, Dimatteo MR. Physician communication and patient adherence to treatment: a meta-analysis. Med Care. 2009;47 (8):826-834. doi:10.1097/MLR.0b013e31819a5acc

45. Checchi KD, Huybrechts KF, Avorn J, Kesselheim AS. Electronic medication packaging devices and medication adherence: a systematic review. JAMA. 2014;312(12):1237-1247. doi:10.1001/ jama.2014.10059

46. Zhang F, Xu H, Chen M, et al. Dose-dependent effect of propranolol on the hemodynamic response in cirrhotic patients with gastroesophageal varices. Eur J Gastroenterol Hepatol. 2019;31(3):368-374. doi:10.1097/MEG.0000000000001293
International Journal of General Medicine

\section{Publish your work in this journal}

The International Journal of General Medicine is an international, peer-reviewed open-access journal that focuses on general and internal medicine, pathogenesis, epidemiology, diagnosis, monitoring and treatment protocols. The journal is characterized by the rapid reporting of reviews, original research and clinical studies across all disease areas. The manuscript management system is completely online and includes a very quick and fair peer-review system, which is all easy to use. Visit http://www.dovepress.com/ testimonials.php to read real quotes from published authors. 